\title{
Comparative Study of the Impact of Class Repetition and Mass Promotion on Students' Academic Achievement in Anambra State
}

\author{
Eboatu, V. N., PhD \\ Department of Educational Management and Policy, \\ Nnamdi Azikiwe University, Awka, Nigeria
}

Doi: 10.19044/esj.2017.v13n28p394 URL:http://dx.doi.org/10.19044/esj.2017.v13n28p394

\begin{abstract}
This study investigated the impact of the practice of class repetition and mass promotion of failed JSS1 students on their academic achievement in Anambra State. The causal comparative or ex-post-facto type of the survey research design was adopted with four research questions and four hypotheses guiding the study. The population of the study consisted of all failed Junior Secondary School (JSS1) students in Anambra State secondary schools in the base year (2004/2005), from which a sample of 636 was drawn. A researcher designed form was used to collect the students' results. The statistical analysis of frequencies, range of scores, percentages and Pearson Product Moment Correlation were used to answer the research questions, while t-test was used to test the hypotheses. Findings of the study, among other things, show that the repeated students made a significant positive change in their repeated JSS1 and that the repeated students' results were significantly better than those of the mass promoted group JSS2 results. Based on the findings, the researcher recommends that educational policy makers adopt an eclectic promotion policy that will enable the school managers repeat students in cases where it is felt that class repetition will enhance students' learning and academic achievement.
\end{abstract}

Keywords: Academic achievements, students

\section{Introduction}

Poor educational achievement is an indicator of educational wastage. Educational wastage implies inefficient use of educational resources which is usually manifested in the form of high failure rates, high class repetition, school drop-out, non-employment of school leavers, brain drain and inadequate utilization of educational resources (Arinze, 1996; World Bank, 2006). 
Class repetition and mass promotion are alternative responses to the problem of poor educational achievement. Until recently, class repetition of failed students has been the usual response to failure in school examinations. Eboatu and Omenyi (2015) observed that most parents, teachers and students have the view that class repetition has a remedial effect on students' academic achievement but this view and the decision to repeat failed students is not backed by empirical studies (IIEP, 1999). Class repetition or grade retention as it is known in other countries, is understood to mean the repetition of a year or grade level or course of study previously failed. It is a get-tough policy that ensures greater accountability and guarantees that the school is doing its job of equipping the students to contribute their quota as members of the society.

According to Stump (2010, p.1) a student could be recommended for class repetition for a variety of reasons which include when a student:

1. has significant struggle making progress academically;

2. fails to reach performance levels expected for promotion to the next level;

3. appears to be immature or young for his/her age;

In practice, class repetition is also recommended when parents request for their children to be repeated, when a student misses too many days of school or when students are deliberately not serious in class and as a result fail their examinations. The repeated groups of students in this study are of all the categories above and did not receive any form of remediation or coaching in their schools. Long (2005) had earlier reported that students who were given remedial courses had better educational outcomes than their counterparts from similar backgrounds who did not.

The practice of class repetition as a means of improving students' academic achievement is rooted in Behaviorist and Cognitive principles of learning, which hold that knowledge acquired must be perfected before any new knowledge could be meaningfully absorbed (Mergel, 1998).

Mass promotion of failed students, otherwise known as social or administrative promotion, is fast replacing class repetition as the alternative response to poor educational achievement. It is an arrangement which allows failed students to proceed to the next higher class despite the fact of failing the previous class. Its proponents argue that in addition to stemming some of the ugly psychological effects of class repetition (Haddad, 1979; Yamamoto, 1980), it helps ensure a more egalitarian distribution of educational access in the sense that unlike class repetition, it eases up students' progression rates and makes it possible for more new entrants to be enrolled in the school system (Hess, 1978; Psacharopoulos, 1985). According to proponents of mass promotion policy in education, class repetition constitutes wastage to 
both public and private funds and makes it impossible for nations to achieve the UN's Education For All (EFA) policy (Nduka, 1996; World Bank, 2006).

Administratively, mass promotion of underperforming students could be done under the ideological principle that keeping students with their cohort and peers is socially essential for their academic success. Rose, Medway, Cantrell and Marus (1983) in Kenny (1989), posit that social promotion helps to reduce the number of over-aged and low-achieving students. It is also pertinent to mention that there are variants of mass promotion. Some education systems practice mass promotion with remediation or intervention, while others do not offer students any form of help. All the schools sampled in this study, did not offer remedial help to the failed students.

According to Steinmayr, Meißner, Weidinger and Wirthwein (2014), Academic achievement represents performance outcomes that indicate the extent to which a person has accomplished specific goals that were the focus of activities in instructional environments, specifically in school, college, and university. According to Arul Lawrence and Vimala (2012), it is a measure of knowledge gained in formal education usually indicated by test scores, grade point average and degrees. It is the application of quality index to educational programmes which is classified by students' grades in terminal and external tests and examinations, and not by the number that made it to the end of the programme. Academic achievement signifies the extent to which the school, teachers and students have achieved the educational goals.

Education is a multi-pronged industry with some of its products intangible and difficult to measure, while some are purely quantitative in nature, such as scoring $40 \%$ in school subjects. For any measure of academic achievement to be valid and effective, it must be curriculum based and capable of giving high coefficients of consistency between the different evaluations at different points in time (Marsh, Parker and Barnes, 1985 and Minnaert, 1991). Mehrens and Lehmann (1978) sadly observe that effective measurement is lacking in schools because academic achievement evaluations don't always focus on the total child. To address this issue, the National Policy on Education (FGN, 2013) prescribes the use of continuous assessment of students in the three domains of knowledge in addition to endof-term/ session examinations. For this reason, this study adopted the analysis of students' end of session examination scores, which is a standardized, accumulative assessment.

This study is hinged on different models of cause and effect theories which support the view that causal ascriptions play major roles as determining academic success. The Self-Determination theory/ model by Deci and Ryan (2002) hypothesized that making students repeat failed classes gives them feelings of failure, humiliation and shame when 
comparing them with their promoted counterparts. Haddad (1979) had earlier contended that class retention of failed students has negative implication for students' self-concept and self-confidence which decreases learning. The feeling of being left behind may ultimately delay the youth's entry into the productive system of the nation and slows down economic development. For these reasons, the Self-Determination theorists favour the practice of mass promotion. Confirming this view, the study of Yamamoto (1980) reported that class repetition could be emotionally damaging and stressful because out of the 20 items on the Child Stress Scale, a majority of students sampled rated class repetition third, just below losing a parent and going blind.

The Maturational Development theorists, Piaget and Inhelder (1967), advocate the cognitive principle that learning is based on the thought process behind the behavior. Learning occurs as a result of association established through mental re-organization and repetition. They therefore posit that early class repetition grants late developers more time to mature cognitively and acquire skills and requisite knowledge that would prevent future failure. Repeating failed classes gives weak-performing students the opportunity to refresh, relearn and experience new success, resulting in feelings of being competent, pleasure of learning, higher motivation and better liking for school. Kenny (1985) reported that parents of repeaters perceived improved emotional maturity and more positive attitudes in their children.

According to Skinner (1953) on operant conditioning to human behaviour, mass promotion of failed students when they don't have competence in the subject matter might send them the wrong message that little is expected of them and they are undeservedly rewarded for not working hard. Given the contentious nature of the mass promotion and class repetition practices, it has become necessary to carry out a study that will elucidate the impact of class repetition and mass promotion of failed students on their academic achievement, because at the moment no such study has, to the best of the researcher's knowledge, been done in Anambra State, Nigeria.

\section{Statement of the Problem}

Poor academic achievement, usually reflected in the form of high student failure in examinations, is a serious index of educational wastage in Anambra State, Nigeria and other developing nations (Ajayi and Mba, 2008; Eboatu, 2013; Psacharopolous, 1985) because it gives rise to class repetition, drop out and non-completion of educational programmes. Class repetition and mass promotion are alternative responses to the problem of failure in examinations but both are contentious issues among educational managers.

Though teachers, parents and even students believe that class repetition has a remedial effect on students' achievements, this belief is not backed by any known study (Eboatu and Omenyi, 2015) and it is believed 
also to have serious negative emotional and psychological effects on students (Yamamoto, 1980). On the other hand, surveys have reported that the rate of class repetition is high in Nigeria (Eboatu, 2013) and other parts of Africa (IIEP, 1999); and that repeaters constitute more than $15 \%$ of the total student enrolment who invariably block access to new entrants. This situation is made more critical by the UN's EFA initiative and the Millennium Development Goals' (MDG) deadline of giving every child a basic education by the year 2015. Given this backdrop, mass promotion becomes an attractive option and a number of Nigerian schools now adopt the practice of mass promotion of failed students to ease up the system and enroll more students. The question still remains, how effective is the practice of mass promotion in giving students functional literacy and numeracy skills. Much of the extant literature on the effect of class repetition and automatic promotion on students' academic achievement are old (Glaziano,1986; Kenn,1988, Kenny,1989 and Karweit andWasik,1992) is old and as at the time of this study there was no information on the impact of mass promotion or class repetition on students' academic achievement in Anambra State, Nigeria.

The problem of this study was, therefore, to determine the comparative impact of class repetition and mass promotion on students' academic achievement in Anambra State of Nigeria.

\section{Purpose of the Study}

Specifically, the purpose of this study was the following -

1. To determine the comparative impact of class repetition and mass promotion on students' mean academic achievement in their JSS1.

2. To determine the comparative impact of class repetition and mass promotion on students' mean academic achievement in their JSS2.

3. To determine correlation coefficient of the repeated students' JSS1 mean academic achievement and their JSS2 mean academic achievement.

4. To determine correlation coefficient of the mass promoted students' JSS1 mean academic achievement and their JSS2 mean academic achievement.

\section{Research Questions}

Four research questions were formulated to guide the study. They are -

1. What is the comparative impact of class repetition and mass promotion on the academic achievement scores of students in their JSS1 in Anambra State? 
2. What is the comparative impact of class repetition and mass promotion on the academic achievement scores of students in their JSS2 in Anambra State?

3. What is the correlation coefficient of the repeated students' JSS1 and JSS2 academic achievement scores in Anambra State?

4. What is the correlation coefficient of the mass promoted students' JSS1 and JSS2 academic achievement scores in Anambra State?

\section{Hypotheses}

1. There is no significant difference in the mean academic achievement scores of repeated JSS1 students and the mean academic achievement score of mass promoted JSS1 students in Anambra State.

2. There is no significant difference in the mean academic achievement scores of repeated students and the mass promoted students in their JSS2 in Anambra State.

\section{Method}

This study adopted the ex-post-facto survey research design which was judged appropriate for determining the impact of class repetition and mass promotion on academic achievement. According to Akuezuilo and Agu (2003), an ex-post-facto design seeks facts associated with occurrences, outcomes, conditions or types of behavior by undertaking the analysis of past or existing conditions.

The sample for this study comprised 636 failed JSS1 students purposively selected from 52 Junior Secondary Schools out of the total number of 260 schools in the State in the 2004/2005 session. 145 of the sample repeated JSS1 while 491 were promoted to JSS2. JSS1 was chosen for this study because it is a foundation class of the secondary level of education. Tracking their academic achievement over three sessions (2004/2005, 2005/2006, 2006/2007) afforded an ample length of time to ascertain the impact of class repetition and mass promotion.

The instrument for data collection was a researcher designed form for collecting the results/ scores of both the repeated group and the mass promoted group in the state-wide end of session examinations in English Language and Mathematics. The Group Aggregate Scores (GAS) in end of session state-wide examination is a standardized test conducted for all schools in the state and is considered an objective measure of students' academic achievement. The instrument was duly validated by one expert each in educational management and measurement evaluation. 
There was, however no need to conduct reliability test on the instrument because the instrument was used for collecting factual information which does not change.

The researcher visited the sampled schools, with the help of two research assistants, to collect the scores of the repeated and mass promoted students. After presenting the letter of introduction and explaining the purpose of the study, the principals of the schools assigned the Deans of Studies and form teachers to make the students' results available in their result booklets/ note books.

Range of scores, frequencies, percentages and Pearson Product Moment ( $r$ ) were used to answer the four research questions, while t-test was used to test the two hypotheses. The test was used because it is an ideal statistic for comparing the means of the two sets of scores. Scores ranging from 0-39 were considered failures while 40-100 were considered pass marks.

\section{Results}

Research Question 1: What is the comparative impact of class repetition and mass promotion on the academic achievement scores of students in Anambra State?

Table 1: Range of Scores, Frequencies and Percentages of Scores of Repeated and Mass Promoted Students.

\begin{tabular}{ccccc}
\hline Range of Scores & \multicolumn{2}{c}{ Repeated Students } & \multicolumn{2}{c}{ Mass Promoted Students } \\
\hline $0-39$ & $\mathrm{~N}$ & $\%$ & $\mathrm{~N}$ & $\%$ \\
$40-100$ & 105 & 72.41 & 491 & 100 \\
Total & 40 & 27.59 & 0 & 0 \\
\hline
\end{tabular}

Table 1 shows that $40(27.59 \%)$ of the 145 repeated students passed their repeated JSS1 with scores ranging from $40-100 \%$. However, the repeated group all failed JSS1 in Anambra State.

Research Question 2: What is the comparative impact of class repetition and mass promotion on the academic achievement scores of students in JSS2 in Anambra State?

Table 2: Range of Scores, Frequencies and Percentages of Scores of Repeated and Mass Promoted Students in JSS2.

\begin{tabular}{ccccc}
\hline Range of Scores & \multicolumn{2}{c}{ Repeated Students } & \multicolumn{2}{c}{ Mass Promoted Students } \\
\hline & $\mathrm{N}$ & $\%$ & $\mathrm{~N}$ & $\%$ \\
$0-39$ & 75 & 51.73 & 390 & 79.43 \\
$40-100$ & 70 & 48.27 & 101 & 20.57 \\
Total & 145 & 100 & 491 & 100 \\
\hline
\end{tabular}


Table 2 indicates that 70 (48.27\%) of the 145 students who failed and repeated JSS1 passed JSS2 by getting average scores ranging from 40 to $100 \%$, while $101(20.57 \%)$ of the 491 mass promoted students passed by attaining average scores ranging from 40 to $100 \%$ in their JSS2. The repeated group had a pass rate of $48.27 \%$ while the mass promoted group had a lower pass rate of $20.57 \%$ in their JSS2.

Research Question 3: What is the correlation coefficient of the repeated students' JSS1 and JSS2 academic achievement scores in Anambra State?

Table 3: Pearson Product Moment (r) of the Repeated Students'JSS1 and JSS2.

\begin{tabular}{cccc}
\hline Source of variation & $\mathrm{N}$ & JSS1r & JSS2r \\
\hline JSS1 & 145 & 1.00 & 0.50 \\
JSS2 & 145 & 0.50 & 1.00 \\
\hline
\end{tabular}

The analysis in Table 3 examines the degree of correlation among the variables in this study: class repetition and academic achievement. The score of repeated students in their JSS1 were correlated with their scores in JSS2 using the Pearson Product Moment Correlation. Table 3 shows that there is an average positive relationship of 0.50 .

Research Question 4: What is the correlation coefficient of the mass promoted students' JSS1 and JSS2 academic achievement scores in Anambra State?

Table 4: Pearson Product Moment (r) of the Mass Promoted Students'JSS1 and JSS2.

\begin{tabular}{cccc}
\hline Source of variation & $\mathrm{N}$ & JSS1r & JSS2r \\
\hline JSS1 & 491 & 1.00 & 0.34 \\
JSS2 & 491 & 0.34 & 1.00 \\
\hline
\end{tabular}

The examination scores of the mass promoted students in their JSS1 and JSS2 examinations were correlated and the result of analysis in Table 4 shows that there is a moderate positive correlation of 0.34 existing between the two sets of scores.

\section{Hypotheses}

H01: There is no significant difference in the mean academic achievement scores of repeated JSS1 students and the mean academic achievement scores of mass promoted JSS1 students in Anambra State.

Table 5: t-test of the Mean Achievement Scores of the Repeated JSS1 and the Mass promoted JSS1 students.

\begin{tabular}{cccccccc}
\hline Source of variation & $\mathrm{N}$ & $\square$ & $\mathrm{Sd}$ & $\mathrm{Df}$ & Cal.t & Crit.t & $\leq$ \\
\hline Repeaters & 145 & 36.96 & 9.26 & & & & \\
Mass Promoted & 491 & 31.23 & 5.08 & & & & \\
\hline
\end{tabular}


Table 5 indicates that the calculated t-value of 9.67 was obtained. With 634 degrees of freedom, at the 0.05 level of significance, the Table value is 1.96 . The summary is that the calculated value (9.67) is greater than the Table value (1.96). The null hypothesis is therefore rejected. The researcher concludes that a significant difference exists between the mean achievement scores of the repeated JSS1 students and the mass promoted JSS1 students.

$\mathrm{HO}_{2}$ There is no significant difference in the mean academic achievement scores of the repeated JSS2 students and the mass promoted JSS2 students' examination scores.

The t-test of the mean achievement scores of repeated JSS2 students and the mass promoted JSS2 scores was computed to determine if a significant difference exists between the two groups' achievements.

Table 6: $t$-test of the Mean Performance Scores of Repeated and Mass Promoted Students in their JSS2.

\begin{tabular}{cccccccc}
\hline Source of variation & $\mathrm{N}$ & $\square$ & $\mathrm{Sd}$ & $\mathrm{Df}$ & Cal.t & Crit.t & $\leq$ \\
\hline Repeaters & 145 & 40.96 & 11.12 & & & & \\
Mass Promoted & 491 & 31.74 & 8.95 & & & & \\
\hline
\end{tabular}

Table 6 shows that the calculated t-value is 9.75 . With 634 degrees of freedom, at 0.05 level of significance, the critical t-value is 1.96 and this is less than the calculated value (9.75). The second null hypothesis of this study stands rejected. A significant difference exists between the academic achievements of the repeaters in JSS2 and that of the mass promoted students in JSS2. The repeated students performed significantly better than the mass promoted group.

\section{Discussion}

The findings of this study show that the repeated students have a significant $27 \%$ improvement in academic achievement in JSS1 compared to the $100 \%$ failure rate of both the mass promoted and repeated group before repetition. This result agrees with Kenny (1988) study which investigated 122 subjects (74 repeaters and 48 mass promoted pupils) in Australia and reported that the repeated students improved by $20 \%$ from time 1 to time 2 . This improvement was however not significant. It appears that having to repeat JSS1 gave some of the repeaters a better and positive attitude to studying. The experience of losing their friends and having to study with their juniors made them sit up in order to avoid repeating again. The UNESCO (IIEP 1999) forum on class repetition participants opined that some teachers use the threat of class repetition to call their students to order. Another reason for improved achievement is that JSS1 is the foundation class of the secondary level of education and repetition afforded the students 
the leverage needed for them to become grounded in the basic knowledge of subjects at that level. Zill, Loomis and West (1997) argued that class repetition is an effective way of allowing late developers to catch up in their studies.

In further analysis of the academic achievement of the repeated and the mass promoted groups in their JSS2 shows that $48.27 \%$ of the repeated group passed while $20.59 \%$ of the promoted group passed. Conversely, in Kenny (1989) study the repeated students improved on the average by $20 \%$ from time 1 to time 2 and by $13 \%$ from time to time 3 while the promoted students' ranking remained unchanged over the four years. The results of this study do not corroborated Kenny's to the extent that while the performance of repeater's increased in the present study, that of Kenny's study regressed. Although both the repeated and mass promoted groups improved their achievements, the t-test analysis shows that the repeated group performed significantly better than the mass promoted group in their JSS2. On the other hand, a comparative study by Karweit and Wasik (1992) reported a favourable effect for class repetition on kindergarten children's academic achievement but that the effect did not persist. Their findings differ to the effect academic gains decreased in subsequent years, while it increased in the present study. It is important to note that $20.59 \%$ of the promoted students passed in JSS2 indicating that the reason for failing in JSS1might not be cognitive but other student, school or homes variables.

The correlation coefficient of the repeated groups JSS1 and JSS2 academic achievement shows an average positive relationship between the students' results. More than half the repeaters who passed their repeated JSS1 continued to improve in their achievement. Conversely, the mass promoted group has a low positive correlation coefficient of 0.34 . This shows that their JSS1 scores do not relate much to their JSS2 results. Most of them must have failed in JSS1 due to lack of hard work or other factors that are not too low I.Q. Kenny (1985) study of socio-emotional effects of class repetition reported that parents of repeated students perceived positive changes in their children's attitudes to school. Further buttressing this view, Plummer, Linberge and Graziano (1986) found that repeated students had more positive self-concept than non-repeaters because of their perceived mastery of the subject matter in the repeated year. It is the opinion of this researcher that students should not be promoted if they are not serious with their studies and as such not ready to progress to the next class or grade. The adoption of a policy of fail-and-repeat helps to pass on the message to students that if they want to be promoted to the next class, they have to sit up. 


\section{Conclusion}

Based on the findings of this study, the researcher concludes that class repetition has more positive and significant impacts on students' academic achievement than mass promotion. The JSS1 and JSS2 achievement scores of the repeated group had a more positive relationship than the mass promoted group. The educational policy maker should adopt class promotion practices that will help maximize students' academic achievement.

\section{Recommendations}

In view of the findings and discussions of this study, the following recommendations are made:

1. The decision to promote or repeat failed students is aimed at improving students' learning and also to accommodate more new entrants into the educational system, the promotion policy should not be too rigid to either adopt only mass promotion or class repetition.

2. Schools should, as a matter of necessity, form Promotions Committees whose duties will include examining every case of failure on its own merits, bearing in mind the peculiar circumstances of each student and making appropriate recommendation. Form teachers and school guidance counselors should be consulted where necessary.

3. The government should consider the introduction of some form of remedial teaching or coaching in schools. Remediation will help failed students improve their academic achievements.

4. School administrators should do well to impress the importance of examination and assessment on students even when mass promotion is practiced. Students should always bear in mind that their performances in internal assessment accounts for $40 \%$ of the final score for their certification

\section{References:}

1. Akuezuilo, E.O. \& Agu, N. (2003). Research Methodology and Statistics. Awka: Nuel Centi (Nig.) Publishers.

2. Ajayi, L.A. \& Mba, G.U. (2008). Trends of Educational Wastage in Ekiti State. Humanity \& Social Science Journal 3(2) 97-103.

3. Arinze, F.O. (1996). Some Issues in Educational Planning, in Bosah and Eneasator (Eds.) Dimensions of Educational Planning and Economics of Education. Lagos: Ed-Solid Foundation Publishers.

4. Arul Lawrence, A.S. \& Vimala, A. (2012). School Environment and Academic Achievement of Standard IX Students. Journal of 
Educational and Instructional Studies in the World. 2(3) 210215.

5. Deci, E.L. \& Ryan, R.M. (2002). Handbook of Self-Determination Research.Rochester: University of Rochester Press.

6. Eboatu, V.N. (2013). Progression Rates of Schools in Awka Education Zone: Vital Data in Effective Educational Planning and Management. Journal of Educational Management and Policy. Vol. 2(2), 156-167.

7. Eboatu, V.N. \& Omenyi, (2015). Impact of Class Repetition on Students' Academic Achievement: Implication on Educational Policy Making. European Scientific Journal (ESJ). Vol. 11(19), 259-267.

8. FGN, (2013). National Policy on Education. Lagos; NERDC.

9. Haddad, W.D. (1979). Educational and Economic Effects of Promotion and Repetition Practices. Staff Working Papers No. 319, Washington D.C.; the World Bank.

10. Hess, F.I. (1978). Promotion versus Non-Promotion: A Policy Review, Issues in Education. Hess et.al (Eds.) Eric Document No. 158398.

11. IIEP (1999). UNESCO/ International Institute for Educational Planning: Forum on Repetition.

12. Karweit N.L. \& Wasik, B.A., (1992). A Review of Effects of ExtraYear Kindergarten Programmes and Traditional First Graders. Washington D.C.; Office of Educational Research and Improvement.

13. Kenny, D.T. (1985). The Effects of Repetition on the Academic Performance of Primary School Repeaters. Australian Journal of Special Education, 9(2), 16- 23.

14. Kenny, D.T. (1988). Grade Repetition: A Three-year Follow-Up. Journal of Remedial Education. 21 (3) 8-11.

15. Kenny, D.T. (1989). The Effects of Grade Repetition on the Social/emotional Adjustments of Infants and Primary School Students. The Australian

16. Educational and Development Psychologists, 6(1), 10-19.

17. Long, B.T. (2005) Remediation: Are We Serving the Needs of Students? Washington D.C. Crosstalk: A Publication of the National Centre for Public Policy and Higher Education.

18. Marsh, Parker and Barnes, (1985). Multidimensional Adolescent Self-Concepts: Their Relationship to Age, Sex and Academic Measures. American Educational Research Journal. 22(3), 422-444.

19. Mehrens, W.A. \& Lehman I.J. (1978). Measurement and Evaluation in Education and Psychology. New York: Holt Renehart and Winston. 
20. Mergel, B. (1989). Constructivism and Instructional Design. Educational Technology, Retrieved: May 1991 pp.45-53. Available: http://www.gwu.edu/tip/militaryhtml

21. Mergel, B. (1998). Instructional Design \& Learning Theory (Master's thesis, University of Saskatchewan). Retrieved: 12/08/2016 http://etad.usask.ca/802papers/mergel/brenda.htm

22. Minnaert, A. (1991). Mathematics Achievement Test End of first Grade A of Secondary School Education. Afdeling Psychodiagnostiek en Psychologische Begeleidung \& Onderzoekscentrum voor Secundair en Hoger Onderwijs

23. Nduka, G.C. (1996). Data for Educational Planning, in Bosah and Eneasator(Eds.) Dimensions of Educational Planning and Economics of Education. Lagos: Ed-Solid Foundation Publishers.

24. Piaget, J. \& Inhelder, B. (1967). A Child's Conception of Space. (Langdon, F.J. \& Lunzer, J.L., Trans.). New York: Norton

25. Plummer, O., Lineberge, M.H. \& Graziano, W.G. (1986). The Academic and Social Consequences of Grade Retention, in Katz, L.G. (Ed.), Current Topics in Early Childhood Education,6, Norwood, NJ: Ablex Publishing.

26. Psacharopolous, G. \& Wood Hall, M. (1985). Education for Development: Analyses of Investment Choices. Oxford University Press (for the World Bank).

27. Skinner, B.F. (1953) Science and Human Behaviour. New York: MacMillan

28. Steinmayr, R., Meißner, A., Weidinger, A., \& Wirthwein, L. (2014), Academic Achievement.

http://www.oxfordbibliographies.com/view/document/obo

9780199756810/obo-9780199756810-0108.xml Retrieved: 2/5/2010

29. Stump, C. (2010). Repeating a Grade: The Pros and Cons. www. greatschools.org/special-education/.../repeatingagrade.gs? Retrieved: $1 / 5 / 2010$.

30. World Bank (2006). World Development Indicators, Washington D.C.: Development Data Centre.

31. Yamamoto, K. (1980). Children Under Stress: The Causes and the Cure. Ogden: Family Weekly. The Standard Examiner.

32. Zill, N., Loomis, L.S., West, J. (1997). The Elementary School Performance and Adjustment of Children Who Enter Kindergarten: Findings from National Surveys. Rockville, MD: Westal Inc. 